\title{
Black Seventh-Day Adventists' Adherence to the Centers for Disease Control and Prevention's 1995 and 2008 Physical Activity Guidelines for Adults
}

\author{
Nicceta Davis ${ }^{1, *}$, Donna Thorpe ${ }^{2}$, Patti Herring ${ }^{3}$, W. Lawrence Beeson ${ }^{4}$, Gary Fraser ${ }^{5}$ \\ ${ }^{1}$ Department of Physical Therapy, School of Allied Health Professions, Loma Linda University, Loma Linda, CA, 92350, USA \\ ${ }^{2}$ Allied Health Studies, School of Allied Health Professions, Loma Linda University, Loma Linda, CA, 92350, USA \\ ${ }^{3}$ Health Promotion and Education Program, School of Public Health, Loma Linda University, Loma Linda, CA, 92350, USA \\ ${ }^{4}$ Epidemiology and Biostatistics Programs, School of Public Health, Loma Linda University, Loma Linda, CA, 92350, USA \\ ${ }^{5}$ Department of Preventive Medicine, School of Medicine, Loma Linda University, Loma Linda, CA, 92350, USA \\ *Corresponding author: ndavis@1lu.edu
}

Received November 12, 2018; Revised December 14, 2018; Accepted December 28, 2018

\begin{abstract}
A lack of physical activity is associated with many chronic and metabolic diseases and decreased life expectancy. This study assessed the physical activity practices of Black Seventh-day Adventists to determine adherence to the Centers for Disease Control and Prevention's 1995 and 2008 guidelines for adult physical activity. Data from 16,547 Black participants of the Adventist Health Study-2 prospective cohort were analyzed. Data about dietary practices, medication usage, and physical activity were collected and analyzed. Only $11.3 \%$ of Black Adventists met 1995 recommended guidelines and 22.8\% met 2008 guidelines. Gender, age, educational level, and body mass index were associated with adherence to 1995 guidelines while gender, educational level, and body mass index were associated with adherence to 2008 guidelines. Compared to respondents 18-44 years (reference), 45-64 and $65+$ years and older were most likely to adhere to 1995 guidelines ( $\mathrm{OR}=1.22,95 \% \mathrm{CI}: 1.07,1.39)$ and $(\mathrm{OR}=1.51$, $95 \%$ CI: $1.27,1.79)$ respectively. Most likely to adhere to 2008 guidelines were respondents aged $45-64$ and $65+$ years and older $(\mathrm{OR}=1.12,95 \%$ CI: $1.03,1.22)$ and $(\mathrm{OR}=1.25,95 \% \mathrm{CI}: 1.10,1.41)$ respectively, and those educated at bachelor's level and higher ( $\mathrm{OR}=1.27,95 \%$ CI: 1.16, 1.43), compared to grades K-12 (reference). Differences in 1995 and 2008 physical activity criteria resulted in differences in adherence, with greater adherence to the 2008 guidelines. Adults should be encouraged to participate in at least 150 minutes of moderate exercise or 75 minutes of vigorous exercise weekly to meet recommended physical activity guidelines.
\end{abstract}

Keywords: black seventh-day Adventists, exercise, physical activity guidelines, health behaviors

Cite This Article: Nicceta Davis, Donna Thorpe, Patti Herring, W. Lawrence Beeson, and Gary Fraser, "Black Seventh-Day Adventists' Adherence to the Centers for Disease Control and Prevention's 1995 and 2008 Physical Activity Guidelines for Adults." Journal of Physical Activity Research, vol. 4, no. 1 (2019): 26-33. doi: 10.12691/jpar-4-1-2.

\section{Introduction}

According to the World Health Organization [1], one of the 10 leading risk factors for death worldwide is insufficient physical activity (PA). Insufficient PA is also a key risk factor for cardiovascular diseases (CVD), some cancers, metabolic disorders, diabetes and other chronic diseases. As high as $80 \%$ of American adults do not meet the Centers for Disease Control and Prevention's (CDC) recommended guidelines for PA and about $45 \%$ are not active enough to achieve many physical health benefits $[2,3]$. Inactivity has had a significant impact on the physical and financial health of Americans and America, accounting for billions of dollars in health care expenditures related to inactivity with $11.1 \%$ of aggregate health expenditures $[4,5]$.
According to the Department of Health and Human Services, $21.4 \%$ of adults met the 2008 physical activity guidelines (PAG) $[3,6]$. A person's perception of and participation in PA can be influenced by gender, age, relationships with others, educational level, and how they view their own body type or morphology. Participation in PA varies by geographic region and age, with people living in the West, Northeast and Midwest being more likely to meet PAG than people living in the South; younger adults more likely than older adults; non-Hispanic White adults more likely than Black and Hispanic adults; males more than females; and individuals who have an exercise companion more than those who don't $[6,7,8]$. Although education does not have a direct effect on PA because of the increased access to resources, increased knowledge of healthful lifestyle practices, human capital and social interactions, individuals with more formal education tend to be more physically active than those with less formal education [9]. 
Health promotion and disease prevention are common topics of discussion by physicians, health educators, healthcare providers, health policy makers and third party insurers. When addressing health promotion and disease prevention, the discussion usually includes two important lifestyle behaviors: diet and exercise [10]. The impact of nutrition, diet and specific foods on health, certain diseases, longevity and mortality is well documented in the literature [11-14] as is PA [1,2,15].

As early as the 1950's, coronary heart disease, a type of CVD, was found to be associated with a lack of PA [16] and inactivity was later recognized as a significant risk factor for the development of coronary heart disease $[2,17]$. In 1995, the CDC and American College of Sports Medicine (ACSM) recommended adults engage in 30 minutes of moderate intensity exercise "most days of the week", with "most days" defined as five or more days per week and daily being preferable [18]. According to Sapkota et al. [19], barriers to engaging in PA included lack of motivation, lack of time and limited access to exercise facilities.

In 2008, PAG for adults (18 - 64 years of age) were revised giving individuals more latitude and flexibility to engage in a variety of activities and time combinations to meet the PAG [20]. The 2008 PAG, which are still in effect, recommend that adults engage in at least 150 minutes of moderate intensity aerobic activity or at least 75 minutes of vigorous intensity aerobic PA per week, and muscle strengthening activities at least two days per week. While PA is defined as anything that gets the body moving [1], the PAG specifically recommends a combination of aerobic and muscle strengthening activities to give the most benefits for health [2]. According to the CDC, light to moderate PA is described as that which causes light sweating or a moderate increase in breathing or heart rate while vigorous PA is described as that which causes heavy sweating or a greater increase in breathing or heart rate [20]. Older adults at least 65 years of age who are looking for greater health benefits from PA are encouraged to engage in 300 minutes or more of moderate intensity aerobic activity per week and muscle strengthening at least two or more days a week, or 150 minutes of vigorous intensity aerobic activity per week and muscle strengthening exercises at least two days per week $[8,20]$.

Healthy lifestyle behaviors are not limited to a national conversation as there are faith-based organizations that also promote health. One such organization is the Seventh-day Adventist (Adventist) church. From its beginnings in the early $1860 \mathrm{~s}$, the Adventist church has encouraged eating nutritious foods, drinking sufficient water, a moderate exposure to sunlight, physical activity, fresh air and getting adequate rest to promote sound health and reduce the risks for chronic diseases [21]. Even in the early 1900s White [21,22,23] wrote about PA and its benefits in promoting the proper digestion of foods, enhancing blood flow, increasing function of all of the body's organs and helping reduce the effects of chronic illnesses. Consequently, many members of the Adventist church have adopted lifestyle behaviors that include a healthy diet and PA, albeit a healthy diet is emphasized and described in more detail than PA [24]. As a result, non-Hispanic White Adventists who live in the United States are known to live $4-10$ years longer and have fewer chronic diseases than their non-Adventist counterparts [25].

Although regular PA is known to positively impact health and is associated with an improved quality of life and longevity, and although regular PA is promoted in society and by the Adventist church, there is a paucity of research specifically addressing PA practices among Adventists in general, and Black Adventists specifically. Therefore, the primary purpose of this study was to assess the PA practices of Black Adventists to determine adherence to the 1995 and 2008 PAG as established by the CDC $[18,20]$. It focused on the questions "Do Black Adventists adhere to the 1995 and 2008 PAG for adults?" and "What are the characteristics of those who do adhere to PAG when considering the factors of gender, age, marital status, educational level and body mass index (BMI)?”

\section{Methods}

\subsection{Participants}

Data from 16,547 Black Adventists who completed a baseline questionnaire from the Adventist Health Study-2 (AHS-2) prospective cohort during 2002 - 2007 were analyzed for this non-experimental cross-sectional study. For the purposes of this study, respondents who identified themselves as African, African American, Caribbean, and or West Indian were classified as Black. They had to be members of the Adventist church, at least 30 years of age, and residents of the United States or Canada. Respondents who reported being diagnosed with diseases of the respiratory system (chronic bronchitis, emphysema, or asthma) were excluded from the study as individuals with respiratory diseases tend to have lower levels and decreased tolerance to PA $[26,27,28]$.

\subsection{Instrumentation}

The AHS-2 48-page enrollment questionnaire was developed based on testing and validation studies done for diet and physical activity [29,30]. The questionnaire, which was reviewed and approved by the Institutional Review Board (IRB) of Loma Linda University, Loma Linda, CA, included six sections that captured information regarding participants' medical history, female medical history, eating habits, physical activity, general food and medication usage practices, and demographics. For the purposes of this study, the data analyzed were from the PA and demographic information sections of the survey. Physical activity questions used for this study pertained to frequency and duration of participation in PA and were validated among Black subjects in a study by Singh, et al. [31].

In this study, PA and exercise are used as synonymous terms. Frequency and duration of exercise from the "Your Physical Activity" section were used to determine adherence to the PAG. The six questions used from the AHS-2 questionnaire were 1) "Do you usually have a regular exercise program?" 2) "How many times per week do you usually engage in regular vigorous activities, such as brisk walking, jogging, bicycling, etc., long enough or 
with enough intensity to work up a sweat, get your heart thumping or get out of breath?" 3) "On average, how many minutes do you exercise each session?" 4) "Do you walk, run, or jog as part of a physical activity program?" 5) 'How many of these 'walk' or 'run' or 'jog' workouts do you usually do per week?" and 6) "What is your average time spent in each 'walk' or 'run' or 'jog' exercise session (excluding rest stages)?"

Questions about exercise were categorized as "vigorous activities" and "walk or run or jog" workouts. Vigorous activities were described as "brisk walking, jogging, bicycling, etc. long enough or with enough intensity to work up a sweat, get your heart thumping, or out of breath". The other category of exercise was described as "walk or run or jog workouts". For these two general categories - "vigorous activities" and "walk or run or jog workouts" - respondents identified how many times per week and how many minutes per session they engaged in exercise.

Five variables - gender, age, marital status, educational level and BMI - were selected to determine which, if any, were associated with adherence to PAG. Age was collapsed into the categories of $30-44 ; 45-64 ; 65$ and older. With the exception of the $30-44$ age category, these categories are consistent with those identified by the CDC [7]. The CDC's minimum age was 18 whereas the minimum age for AHS-2 participants was 30 years of age. Marital status was collapsed into four categories: 1) "Single", 2) "Married" which included $1^{\text {st }}$ marriage, remarried, common law marriage and separated, 3) "Divorced", or 4) "Widowed". Educational level was collapsed into three categories: 1) "K-12" for individuals who completed grade school or high school, 2) "Some college" for those receiving a trade school diploma and completing some college, and 3) "College" for those who earned a Bachelors' degree or above. The last variable assessed was BMI. While BMI does not measure fat directly, it is correlated with skin fold and body fat measures which are affected by PA. Higher BMIs are associated with higher overall mortality [32]. The following BMI classifications were made based on the CDC parameters: 1) underweight, $\left.\left(<18.5 \mathrm{~kg} / \mathrm{m}^{2}\right), 2\right)$ normal or healthy weight, $\left.\left(18.5-24.9 \mathrm{~kg} / \mathrm{m}^{2}\right), 3\right)$ overweight, $\left(25-29.9 \mathrm{~kg} / \mathrm{m}^{2}\right)$, and 4$)$ obese, $\left(>30 \mathrm{~kg} / \mathrm{m}^{2}\right)$ [32]. Body mass index (BMI) was calculated using height and weight from the self-reported data from the validated questionnaire [33].

\subsection{Adherence to CDC Physical Activity Guidelines}

The two outcome variables for the study were adherence to the $1995 \mathrm{PAG}$ and adherence to the 2008 PAG. Based on the CDC's description of adherence, we determined that a person met the 1995 PAG if they performed vigorous exercise and/or walked, ran, or jogged 30 or more minutes, five or more days per week [18]. They met 2008 PAG if their moderate intensity workouts" equaled or exceeded 150 minutes per week or their "vigorous activities" equaled or exceeded 75 minutes per week [20]. Minutes reported as running, or jogging at a 4 mph pace were considered vigorous and a pace greater than $2.5 \mathrm{mph}$ but less than 4 was considered a moderate intensity workout [34].

\subsection{Procedures}

Black participants of the AHS-2 were recruited between 2002 and 2007 from approximately 1,000 predominately Black churches in the U.S. and Canada. Understanding the challenge of enrolling Blacks in research studies, the co-investigators of AHS-2 developed a recruitment approach which included personal contact with Black Adventist administrators, church pastors, and church health coordinators. Pastors and church recruiters received a modest monetary incentive for their efforts to enroll Blacks from local church congregations into the study [35, 36]. AHS-2 personnel traveled to predominately Black Adventist churches to conduct in-services and to train local church health coordinators about the purpose of the AHS-2 study, the enrollment process and procedures for completing and returning questionnaires. Returned questionnaires were optically scanned into an analytical master file. As a part of this on-going study, mailings are sent to AHS-2 participants every two years during followup to assess various health changes, hospitalizations and or newly diagnosed diseases. To date, subsequent biennial mailings have not, however, focused on changes in PA.

\subsection{Data Analysis}

Descriptive statistics were calculated to determine the proportion of Black Adventists who met both 1995 and 2008 PAGs. Chi-square tests for independence were calculated to test the hypotheses of association between adherence to 1995 and 2008 PAG and the five explanatory variables. The characteristics of those most likely and least likely to adhere to the 1995 and 2008 PAG were identified using multivariable logistic regression. We focused on the variables: gender, age, marital status, education and BMI to assess relationships with adherence to PA. All analyses were completed using SAS (ver 9.4, SAS Institute, Inc., Cary, NC).

\section{Results}

The variables considered in this study were gender, age, marital status, educational level and BMI. The mean age of respondents was 52.1 years (SD 12.9). Sixty-nine percent were female, almost $70 \%$ over the age of $45,65 \%$ married, almost $79 \%$ had trade school education, some college or were college graduates, and the predominance of respondents, $69 \%$, were overweight or obese. See Table 1.

Eleven percent (11.3\%) of respondents met the 1995 PAG and $22.7 \%$ met the 2008 PAG. Table 2 shows univariate associations of adherence to the 1995 and 2008 PAG's. Gender, age, education and BMI were significantly associated with adherence to the 1995 PAG. Only gender, education, and BMI were significantly associated with adherence to 2008 PAG. 
Table 1. Descriptive Statistics Of Characteristics Of Black Seventh-day Adventists For Selected Explanatory Variables

\begin{tabular}{|c|c|c|}
\hline & $\mathrm{N}=16,547$ & $\%$ \\
\hline \multicolumn{3}{|l|}{ Gender } \\
\hline Male & 5106 & 31.0 \\
\hline Female & 11441 & 69.0 \\
\hline \multicolumn{3}{|l|}{ Age Categories } \\
\hline $30-44$ & 5161 & 31.2 \\
\hline $45-64$ & 8366 & 50.6 \\
\hline 65 - Older & 3020 & 18.2 \\
\hline \multicolumn{3}{|l|}{ Marital Status } \\
\hline Single & 2116 & 12,8 \\
\hline Married & 10759 & 65.0 \\
\hline Divorced & 2446 & 14.8 \\
\hline Widowed & 1226 & 7.4 \\
\hline \multicolumn{3}{|l|}{ Educational level } \\
\hline $\mathrm{K}-12$ & 3488 & 21.1 \\
\hline Some college, trade & 6662 & 40.3 \\
\hline College Graduate & 6397 & 38.6 \\
\hline \multicolumn{3}{|l|}{$\operatorname{BMI}\left(\mathrm{kg} / \mathrm{m}^{2}\right)$} \\
\hline$<18.5$ Underweight & 219 & 1.3 \\
\hline $18.5-24.9$ Normal & 4865 & 29.5 \\
\hline $25-29.9$ Overweight & 6294 & 38.0 \\
\hline$\geq 30$ Obese & 5169 & 31.2 \\
\hline
\end{tabular}

Table 2. Univariate Associations Between Selected Explanatory Variables And Adherence To 1995 And 2008 Physical Activity Guidelines Among Black Seventh-day Adventists Using Chi-square Test Statistics From An Overall Sample, N = 16,547

\begin{tabular}{|c|c|c|c|c|c|c|c|c|c|c|}
\hline & \multicolumn{4}{|c|}{ Adherence to 1995 PAG n=13,606 } & \multirow[t]{3}{*}{$p^{*}$} & \multicolumn{4}{|c|}{ Adherence to 2008 PAG n=15623 } & \multirow[t]{3}{*}{$p^{*}$} \\
\hline & \multicolumn{2}{|c|}{ Yes } & \multicolumn{2}{|c|}{ No } & & \multicolumn{2}{|c|}{ Yes } & \multicolumn{2}{|c|}{ No } & \\
\hline & $\mathbf{n}$ & $(\%)$ & $\mathbf{n}$ & (\%) & & $\mathbf{n}$ & (\%) & $\mathbf{n}$ & $(\%)$ & \\
\hline Gender & & & & & $<0.001$ & & & & & $<0.001$ \\
\hline Male & 566 & $(13.6)$ & 3604 & $(86.4)$ & & 1257 & $(25.9)$ & 3604 & $(74.1)$ & \\
\hline Female & 971 & $(10.3)$ & 8465 & $(89.7)$ & & 2297 & $(21.3)$ & 8465 & $(78.7)$ & \\
\hline Age & & & & & $<0.001$ & & & & & 0.38 \\
\hline $30-44$ & 433 & $(9.9)$ & 3931 & $(90.1)$ & & 1087 & $(21.7)$ & 3931 & $(78.3)$ & \\
\hline $45-64$ & 786 & $(11.4)$ & 6127 & $(88.6)$ & & 1827 & $(23.0)$ & 6127 & $(77.0)$ & \\
\hline 65 and older & 318 & $(13.3)$ & 2011 & $(86.4)$ & & 640 & $(24.1)$ & 2011 & (75.9) & \\
\hline Marital Status & & & & & 0.41 & & & & & 0.09 \\
\hline Single & 208 & (11.8) & 1553 & $(88.2)$ & & 470 & $(23.2)$ & 1553 & $(76.8)$ & \\
\hline Married & 979 & $(11.0)$ & 7909 & $(89.0)$ & & 2319 & $(22.7)$ & 7909 & $(77.3)$ & \\
\hline Divorced & 245 & $(12.2)$ & 1761 & $(87.8)$ & & 554 & $(23.9)$ & 1761 & $(76.1)$ & \\
\hline Widowed & 105 & $(11.0)$ & 846 & $(89.0)$ & & 211 & (20.9) & 846 & $(80.0)$ & \\
\hline Education & & & & & 0.04 & & & & & $<0.001$ \\
\hline $\mathrm{K}-12$ & 309 & $(11.2)$ & 2459 & $(88.8)$ & & 635 & $(20.5)$ & 2459 & $(79.5)$ & \\
\hline Some college & 575 & $(10.4)$ & 4948 & $(89.6)$ & & 1363 & $(21.6)$ & 4948 & $(78.4)$ & \\
\hline Bachelors \& above & 653 & $(12.3)$ & 4662 & $(87.1)$ & & 1556 & $(25.0)$ & 4662 & $(75.0)$ & \\
\hline $\operatorname{BMI}\left(\mathrm{kg} / \mathrm{m}^{2}\right)^{4}$ & & & & & $<0.001$ & & & & & $<0.001$ \\
\hline$<18.5$ Underweight & 20 & (11.9) & 164 & $(89.1)$ & & 35 & $(17.6)$ & 164 & $(82.4)$ & \\
\hline $18.5-24.9$ Normal & 519 & (12.9) & 3519 & $(87.2)$ & & 1121 & $(24.2)$ & 3519 & $(75.8)$ & \\
\hline $25-29.9$ Overweight & 647 & $(12.8)$ & 4429 & $(87.2)$ & & 1495 & $(25.2)$ & 4429 & $(74.8)$ & \\
\hline
\end{tabular}

* Chi-square test of independence calculated using SAS.

Corresponding multivariate associations with odds ratios for all variables for 1995 and 2008 PAG were analyzed using multiple logistic regression, as shown in Table 3. The significant multivariate predictors for adherence to the 1995 PAG were female (inverse), age (positive), marital status (inverse) and obesity (inverse).
When the 2008 criteria were applied, all variables were found to be significant predictors of adherence to the PAG. Those most likely to adhere to 2008 PAG were respondents older than 45 years of age and those educated at a bachelor's level or above. Females, widowed, and obese respondents were least likely to adhere to the 2008 PAG. 
Table 3. Characteristics Of Black AHS-2 Participants Who Were More Likely To Meet The 1995 And 2008 Physical Activity Guidelines

\begin{tabular}{|c|c|c|c|c|}
\hline & \multicolumn{2}{|c|}{1995} & \multicolumn{2}{|c|}{2008} \\
\hline & \multicolumn{2}{|c|}{ OR $(95 \% \mathrm{CI})$} & \multicolumn{2}{|c|}{ OR $(95 \% \mathrm{CI})$} \\
\hline \multicolumn{5}{|l|}{ Gender } \\
\hline Male & 1.0 (reference) & & 1.0 (reference) & \\
\hline Female & $0.75(0.67,0.84)$ & $\mathrm{p}<0.001$ & $0.81(0.74,0.88)$ & $\mathrm{p}<0.001$ \\
\hline \multicolumn{5}{|l|}{ Age } \\
\hline $18-44$ & 1.0 (reference) & & 1.0 (reference) & \\
\hline $45-64$ & $1.22(1.07,1.39)$ & $\mathrm{p}=0.002$ & $1.12(1.03,1.22)$ & $\mathrm{p}=0.01$ \\
\hline 65 and older & $1.51(1.27,1.79)$ & $\mathrm{p}<0.001$ & $1.25(1.10,1.41)$ & $\mathrm{p}=0.004$ \\
\hline \multicolumn{5}{|l|}{ Marital Status } \\
\hline Single & 1.0 (reference) & & 1.0 (reference) & \\
\hline Married & $0.79(0.67,0.93)$ & $\mathrm{p}=0.005$ & $0.90(0.79,1.02)$ & $\mathrm{p}=0.19$ \\
\hline Divorced & $0.99(0.81,1.21)$ & $\mathrm{p}=0.70$ & $1.02(0.87,1.19)$ & $\mathrm{p}=0.89$ \\
\hline Widowed & $0.78(0.59,1.02)$ & $\mathrm{p}=0.08$ & $0.73(0.59, .90)$ & $\mathrm{p}=0.01$ \\
\hline \multicolumn{5}{|l|}{ Education } \\
\hline $\mathrm{K}-12$ & 1.0 (reference) & & 1.0 (reference) & \\
\hline Some college & $0.98(0.83,1.13)$ & $\mathrm{p}=0.74$ & $1.09(0.98,1.21)$ & $p=0.10$ \\
\hline Bachelors \& above & $1.14(0.98,1.32)$ & $\mathrm{p}=0.08$ & $1.27(1.16,1.43)$ & $\mathrm{p}<0.001$ \\
\hline \multicolumn{5}{|l|}{$\operatorname{BMI}\left(\mathrm{kg} / \mathrm{m}^{2}\right)$} \\
\hline$<18.5$ Underweight & $0.80(0.49,1.29)$ & $\mathrm{p}=0.36$ & $0.67(0.46, .97)$ & $\mathrm{p}=0.03$ \\
\hline $18.5-24.9$ Normal & 1.0 (reference) & & 1.0 (reference) & \\
\hline $25-29.9$ Overweight & $0.97(0.86,1.10)$ & $\mathrm{p}=0.63$ & $1.06(0.98,1.16)$ & $\mathrm{p}=0.22$ \\
\hline$\geq 30$ Obese & $0.62(0.53,0.71)$ & $\mathrm{p}<0.001$ & $0.74(0.67,0.82)$ & $\mathrm{p}<0.001$ \\
\hline
\end{tabular}

${ }^{\text {a }}$ Odds ratios were created by multivariable logistic regression. All variables were in each of the two (1995 and 2008) logistic regression models.

\section{Discussion}

Study findings revealed Black Adventists' adherence to the 2008 PAG $(22.7 \%)$ was better than their adherence to the 1995 PAG (11.3\%) and non-Adventist Blacks' adherence to the 2008 PAG (19.8\%) [37]. Data were not available for non-Adventist Blacks' adherence to the 1995 PAG. The increase in the proportion of Black Adventists' adherence to the PAG from 1995 to 2008 was due to the change in the criteria for adherence as opposed to a change in the frequency and or duration of physical activity. The change in the CDC's guidelines suggests the 150 minutes total of PA per week are as effective in providing health benefits as the 1995 PAG provided $[38,39]$.

The second question considered was "What are the characteristics of those who do adhere to PAG when considering the factors of gender, age, marital status, educational level and BMI?" The nature of cross-sectional study designs does not lend itself to testing hypotheses of true cause and effect relationships but there are characteristics that could be considered both a cause and or effect to the adherence to PAG.

When gender was considered, females were less likely than males to adhere to the 1995 and 2008 PAG which is consistent with Blackwell's report [7]. Reported barriers for females participating in PA include a lack of time, motivation, access to childcare, knowledge regarding the benefits of exercise, and the challenge of hair maintenance [40,41,42]. Although the World Health Organization's definition of PA states any bodily movement produced by skeletal muscle and requiring energy qualifies as PA [1], it is possible that females do not view the physical activity associated with the demands of managing the family schedules, household chores, day to day operations of the home, work outside of the home, childrearing and, with increasing frequency, caring for parents as appropriate to report as PA or exercise.

When age was considered as a predictor of PA, we found respondents 45-64 years of age and 65 years and older were more likely to adhere to both the 1995 and 2008 PAG than respondents under the age of 45 years. Possible reasons for this are that as people grow older, childcare and family responsibilities and professional and career advancement activities lessen, which leads them to reprioritize their life activities to include PA in daily activities. Those most likely to adhere to 1995 and 2008 PAG were respondents over 65 years who may have been retired and therefore able to commit more time to PA. Additionally, PA is associated with improved health, quality of life, maintaining independence and increased longevity. These benefits lead older people to make time for and create opportunities to participate in PA $[43,44,45,46]$.

Marital status was inversely associated with adherence to PAG for 1995 and 2008. Married individuals were least likely to adhere to the 1995 PAG and widowed individuals to the 2008 PAG. Smith [47] reported social support, particularly from family members, was associated with increased participation in PA. Assuming marriages provide social support, it is somewhat surprising that married respondents were inversely associated to the 1995 PAG. Assuming widowed respondents may have less social support than those who are married, the inverse association to PA was not surprising. Widowed adults may benefit from participation in activities that promote interaction and socialization with other adults which may include or encourage PA $[47,48]$. 
Individuals with more formal education tend to be more physically active then those with less formal education $[3,9]$, therefore, we expected respondents with some college education or above to be more likely to adhere to PAG. When the 1995 PAG were applied respondents with a bachelors and above were more likely to adhere to PAG than those in the K-12 and some college categories but the highest educational category, bachelors and above, was not a significant predictor for adherence to 1995 PAG which is consistent with Assari's [49] findings. When the 2008 PAG were applied those with a bachelors or above were significantly more likely to adhere to the PAG. No doubt it was the change in criteria that allowed for adherence to the 2008 PAG. The total time of 150 or 75 minutes per week for moderate and vigorous PA was more attainable than achieving a specific amount of time for a specific number of days per week as required by the 1995 PAG.

The last variable considered was BMI which is a surrogate of a person's body fat. Respondents of the AHS2 who were in the obese category were least likely to adhere to the 1995 and 2008 PAG. It should be noted, however, that of the $11.3 \%$ of respondents who met the 1995 PAG, 67\% were identified as overweight or obese and of the $22.7 \%$ who met the 2008 PAG, 65\% were identified as overweight or obese. This suggests other factors than PA are at play when considering BMI and adherence to PA does not necessarily translate into normal BMI. Participating in PA should not lead individuals to believe they can neglect other factors that would reduce the chance of being overweight or obese, such as proper diet, portion control, getting adequate rest, etc. This is an important point because obesity is a risk factor for many diseases and disorders which include stroke, type 2 diabetes, CVD, metabolic disorders, and some cancers [50]. According to Singh and colleagues [51], Black Adventists who were obese experienced a significant 6-year decrease in life expectancy. In addition to being instructed and encouraged to meet PAG, people should be informed of the benefits of practicing many other positive lifestyle behaviors that will reduce the risk of being overweight or obese and promote health.

The barriers to participating in PA were not intentionally explored or reported in the AHS-2, but it is possible some of the barriers reported by Sebastião [52] and Siddiqi [53] hold true for AHS-2 respondents also. Barriers could include a lack of understanding of the educational materials and instructions that promote PA; educational materials that did not reflect or illustrate attitudes Blacks could relate to; a lack of time, motivation, knowledge; health conditions such as joint pain and injuries. These barriers can be mitigated with more appropriate educational materials developed by authors who understand and are sensitive to different learning styles and the cultural influence of the Black community. Educational classes that focus on the value of PA to reduce and prevent chronic diseases, benefits to overall health, reduction of joint pain and injuries and the increased life expectancy, would be beneficial. Additionally, social and environmental barriers included a lack of access to childcare, major family responsibilities, lack of financial resources to join fitness clubs, neighborhood safety problems and heavy traffic resulting in ambient air pollution. As people begin to understand and appreciate that there are health benefits to participating in PA for as few as 10 minute increments to accrue 150 per week, they may be more inclined to commit to PA which will allow them to meet the 2008 PAG.

The CDC's 2008 PAG, which recommend a person perform vigorous activity for 75 minutes or moderate activity for 150 minutes per week, allows for a variety of activities that can promote and enhance health [2]. Many people have psychological barriers to exercise related to self-efficacy or feeling they are not capable of achieving exercise goals [54]. The flexibility and variety of activities and times needed to meet PAG allow to people meet the standard without performing extraordinary feats or committing hours and hours to PA. Physicians, health educators and health care providers should consider psychological barriers related to self-efficacy and encourage their patients that they can achieve the broad 2008 PAG by making simple changes in lifestyle behaviors. Additionally, religious leaders should be educated about 2008 PAG and encouraged to participate and promote PA in their congregations. Religious leaders can be effective in conveying that message because of their influence in the community, their credibility, ability to communicate, and mastery of scripture that espouse virtues of healthy living [55].

\subsection{Study Strengths and Limitations}

As James et al. [56] noted, recruitment of Blacks for research studies is challenging and must be approached differently than routine recruitment strategies that are effective in other cultures. The large sample size for this study $(n=16,547)$, which was achieved in part by the recruitment strategies used for recruiting Blacks $[35,36]$ is a strength of this study. The differences noted in Black Adventists' adherence to PAG from 1995 to 2008 were based on changes in the guidelines, not changes in PA because essentially the same data were used for both analyses. A recommendation for future study is that participants be queried periodically about their level of PA to determine what changes may have occurred to determine if adherence to PAG improves.

A limitation to the study was that because barriers to participating in PA were not reported, we can only surmise that the many barriers identified in other studies, i.e., lack of time, resources, environmental barriers, also operate among Black Adventists [52,53]. It should be noted that the nature of cross-sectional study designs does not allow for assessment of changes in participants' PA over time nor can true cause-effect relationships be convincingly established.

Self-reported data on PA must be considered cautiously as participants tend to over-estimate PA levels [57,58] which may have been the case with this report. As mentioned previously some females may have under-reported their PA because they did not consider the energy expended in their daily routines qualified as PA. The use of pedometers, accelerometers or other motion sensors (e.g., apps on smart phones) would give more accurate and objective data to determine PA for determining adherence.

This analysis addressed PA but did not address other factors such as exercise intensity and diet as we were 
concerned primarily with Black Adventists' adherence to PAG based on their self-reported data. Suggestions for future research include longitudinal studies of Black Adventists 1) to assess the relationship between adherence to PAG and exercise intensity, 2) diet and PA and how an individual's commitment to healthy lifestyle behaviors may inform, influence, or motivate them to participate in regular PA, 3) the PA behaviors of Black Adventists who have diabetes and other chronic and metabolic disorders, and 4) the PA behaviors of Black Adventists diagnosed with osteoarthritis of the extremities or spine.

While the data for this study were collected as early as 2002 and are therefore outdated, the associations observed between PA and characteristics that tend to facilitate PA and barriers to PA can be instructive.

\section{Conclusion}

The CDC has established PAG which, if followed, can improve adults' overall health and health outcomes and reduce the risks for cardiovascular diseases, stroke, type 2 diabetes, metabolic disorders and some cancers, which are also related to being overweight or obese. We conclude that the PAG 2008 allow for more flexibility in reporting and achieving adherence. Although Black Adventists' adherence to PA is better than that of non-Adventist Blacks, Black Adventists' adherence falls short of ideal PA levels. Older individuals' age and those with the highest level of formal education may help motivate them to be physically active while being female, widowed, and younger were associated with lower adherence which may be related to social and environmental factors. Those who were overweight were also less likely to adhere to the guidelines. Being overweight may be a primary reason individuals are not physically active or they may not be physically active because they are overweight. Health care providers, health educators, policy makers and environmentalists should work together to develop strategies that can reduce or eliminate barriers to PA and encourage compliance with the CDC's PAG.

\section{Acknowledgements}

This research was conducted without support from any funding agency in the public, commercial, or not-forprofit sectors.

\section{Statement of Competing Interests}

The authors of this study have no direct or indirect potential competing interests related to this research.

\section{Abbreviations}

Adventist Health Study-2 (AHS-2)

American College of Sports Medicine (ACSM)

Body mass index (BMI)

Cardiovascular disease (CVD)

Centers for Disease Control and Prevention (CDC)
Coronary artery disease (CAD)

Physical activity (PA)

Physical activity guidelines (PAG).

\section{References}

[1] World Health Organization. Physical activity fact sheet. In: Media centre.

http://www.who.int/mediacentre/factsheets/fs385/en. Accessed 29 June 2018.

[2] Physical inactivity in the United States. In: The state of obesity: Better policies for a healthier America.

http://stateofobesity.org/physical-inactivity/. Accessed 27 June 2018.

[3] Centers for Disease Control and Prevention. Nutrition, physical activity and obesity: data, trends, and maps. https://nccd.cdc.gov/NPAO DTM/IndicatorSummary.aspx?catego ry=71\&indicator=36. Accessed 29 June 2018.

[4] Carlson SA, Fulton JE, Pratt M, Yang Z, Adams KE. Inadequate physical activity and health care expenditures in the United States. Prog Cardiovasc Dis. 2015; Epub 2014 Aug 9.

[5] Ding D, Kolbe-Alexander T, Nguyen B, et al. The economic burden of physical inactivity: a systematic review and critical appraisal. Br J Sports Med. 2017; 51:1392-1409.

[6] Centers for Disease Control and Prevention. National Center for Health Statistics.

http://ftp.cdc.gov/pub/Health_Statistics/NCHS/NHIS/SHS/2014_S HS Table A-14.pdf. Accessed 28 June 2018.

[7] Blackwell DL, Lucas JW, Clarke TC. Summary health statistics for U.S. adults: National Health Interview Survey, 2012. In: Vital and health statistics. Series 10, Data from the National Health Survey. 2014. http://www.ncbi.nlm.nih.gov/pubmed/24819891. Accessed 28 June 2018.

[8] Victor CR, Rogers A, Woodcock A, Beighton C, Cook DG, Kerry SM, Iliffe S, Whincup P, Ussher M, Harris TJ. What factors support older people to increase their physical activity levels? An exploratory analysis of the experiences of PACE-Lift trial participants. Arch Gerontol Geriatr. 2016; 67: 1-6.

[9] Pamel FC, Krueger PM, Denney JT. Socioeconomic disparities in health behaviors. Annu Rev Socio. 2010; 36: 349-70.

[10] Lanier JB, Bury DC, Richardson SW. Diet and physical activity for cardiovascular disease prevention. Am Fam Physician. 2016; 93:919-24.

[11] Orlich MJ, Fraser GE. Vegetarian diets in the Adventist Health Study 2: A review of initial published findings. Am J Clin Nutr. 2014; June (100):353S-358S. Epub 2014 Jun 4.

[12] Fraser G, Katuli S, Anousheh R, Knutsen S, Herring P, Fan J. Vegetarian diets and cardiovascular risk factors in Black members of the Adventist Health Study-2. Public Health Nutr. 2015; Epub 2014 Mar 17.

[13] Orlich MJ, Singh PN, Sabate J, Jaceldo-Siegl K, Fan J, Knutsen S, Beeson L, Fraser GE. Vegetarian dietary patterns and mortality in Adventist Health Study 2. JAMA Intern Med. 2013.

[14] Tantamango YM, Knutsen SF, Beeson WL, Fraser G, Sabaté J. Foods and food groups associated with the incidence of colorectal polyps: The Adventist Health Study. Nutr Cancer. 2011.

[15] Long G, Watkinson C, Brage S, Morris J, Tuxworth B, Fentem P, Griffin S, Simmons R, Wareham N. Mortality benefits of population-wide adherence to national PA guidelines: a prospective cohort study. Eur J Epidemiol. 2014.

[16] Powell KD, Thompson PD, Caspersen CJ, Kendrick JS. Physical activity and the incidence of coronary heart disease. Ann Rev Public Health. 1987; 8: 235-87.

[17] Bijnen FCH, Caspersen CJ, Mosterd WL. Physical inactivity as a risk factor for coronary heart disease: a WHO and International Society and Federation of Cardiology position statement. Bulletin of the World Health Organization. 1994; 72: 1-4.

[18] Pate RR, Pratt M, Blair SN, Haskell WL, Macera CA, Bouchard C. Physical activity and public health. A recommendation from the Centers of Disease Control and Prevention and the American College of Sports Medicine. JAMA. 1995; 273 (5): 402-07.

[19] Sapkota S, Bowles HR, Ham SA., Kohl HW. Adult participation in recommended levels of physical activity-United States 20012003. In: Morbidity and Mortality Weekly Report. 2005. 
http://www.cdc.gov/mmwr/preview/mmwrhtml/mm5447a3.htm. Accessed 29 June 2018.

[20] How much physical activity do adults need? CDC Retrieved from http://www.cdc.gov/physicalactivity/everyone/guidelines/adults.ht $\mathrm{ml}$. Accessed 28 June 2018.

[21] White EG. The Ministry of Healing. Pacific Press Publishing Association: Boise, ID; 1905.

[22] White EG. Counsels on Diet and Foods. Review and Herald Publishing: Hagerstown, MD; 1938.

[23] White EG. Counsels on Health. Pacific Press: Boise, ID; 1923.

[24] Seventh-day Adventist Church. Living a healthful life. https://www.adventist.org/en/vitality/health/. Accessed 28 June 2018.

[25] Fraser GE, Shavlik DJ. Ten years of life: Is it a matter of choice? Arch Intern Med. 2001; 161(13): 1645-1652.

[26] Celli BR. Predictors of mortality in COPD. Respir Med. 2010; June 104: 773-9.

[27] duBois RM, Albera C, Bradford WZ, Costabel U, Leff JA, Noble PW, Sahn SA, Valeyre D, Weycker D, King TE. 6-Minute walk distance is an independent predictor of mortality in patients with idiopathic pulmonary fibrosis. Eur Respir J. 2014; 43:1421-29.

[28] Saunders T, Campbell N, Jason T, Dechman G, Hernandez P, Thompson K, Blanchard CM. Objectively measured steps/day in patients with chronic obstructive pulmonary disease: a systematic review and meta-analysis. J Phys Act Health. 2016; 13(11): 1275-1283.

[29] Butler TL, Fraser GE, Beeson WL, Knutsen SF, Herring RP, Chan J, Sabaté J, Montgomery S, Haddad E, Preston-Martin S. Cohort profile: The Adventist Health Study-2 (AHS-2). Int J Epidemiol. 2008; 37:260-65.

[30] Jaceldo-Siegl K, Knutsen SF, Sabaté J, Beeson WL, Chan J, Herring RP, Butler TL, Haddad E, Bennett H, Montgomery S, Sharma SS, Oda K, Fraser GE. Validation of nutrient intake using a food-frequency questionnaire and repeated $24 \mathrm{~h}$ recalls in Black and White subjects of the Adventist Health Study-2 (AHS-2). Public Health Nutrition. 2010; 13: 812-19.

[31] Singh PN, Fraser GE, Knutsen SF, Lindsted KD, Bennett HW. Validity of a physical activity questionnaire among AfricanAmerican Seventh-day Adventists. Med Sci Sports Exerc. 2001; 33: 468-75.

[32] Centers for Disease Control and Prevention. Healthy weight. http://www.cdc.gov/healthyweight/assessing/bmi/index.html. Accessed 28 June 2018.

[33] Bes-Rastrollo M, Sabaté J, Jaceldo-Siegl K, Fraser GE. Validation of self-reported anthropometrics in the Adventist Health Study 2. BMC Public Health. 2011; 11: 213.

[34] Williams PT, Thompson PD. The relationship of walking intensity to total and cause-specific mortality. Results from the National Walkers' Health Study. PLOS ONE 2013; 8:1-10.

[35] Herring RP, Montgomery S, Yancey AK, Williams D, Fraser GE. Understanding the challenges in recruiting Blacks to a longitudinal cohort study: The Adventist Health Study. Ethnicity \& Dis. 2004; 14: 423-30.

[36] Yancey AK, Herring RP, Fraser GE, Yan R, Baker P, Lampkin A, Kyle J. Black art posters, an incentive to increase study enrollment among Blacks in a large cohort study. Prev Med. 2008; 46: 370-73.

[37] National Health Interview Survey, family core and sample adult questionnaires.

http://www.cdc.gov/nchs/hus/contents2016.htm\#057. Accessed 28 June 2018.

[38] O'Donovan G, Blazevich AJ, Boreham C, et al. The ABC of physical activity for health: a consensus statement from the British Association of Sport and Exercise Sciences. J Sports Sci. 2010; 28: 573-91.

[39] Schoenborn CA, Stommel M. Adherence to the 2008 physical activity guidelines and mortality risk. Am Jou of Preventive Med. 2011; 40(5): 514-21.
[40] Gothe NP, Kendall BJ. Barriers, motivations, and preferences for physical activity among female African American older adults. Gernotol Geriatr Med. 2016; 2.

[41] Huebschann AG, Campbell LJ, Brown CS, Dunn AL. My hair or my health: Overcoming barriers to physical activity in African American women with a focus on hairstyle-related factors. Women \& Health. 2016; 56: 428-47.

[42] Bowen F, O'Brien-Richardson P. Cultural hair practices, physical activity and obesity Journal AANP 2017; 29; 754-62.

[43] Atchley RC. A continuity theory or normal aging. Gerontologist. 1989; 29: 183-90.

[44] Barengo NC. Leisure-time physical activity reduces total and cardiovascular mortality and cardiovascular disease incidence in older adults. J Am Geriatr SOC. 2017; 65: 504-04.

[45] Wanigatunga AA, Tudor-Locke C, Axtell RS, et al. Effects of a long-term physical activity program on activity patterns in older adults. Med Sci Sports Exerc. 2017; 49: 2167-75.

[46] Marzetti, E., Calvani, R., Tosato, M. et al. Aging Clin Exp Res. 2017; 29:35.

[47] Smith GL, Banting L, Eime R, O'Sullivan G, van Uffelen JGZ. The association between social support and physical activity in older adults: a systematic review. Int Behav Nutr Phys Act. 2017; 14: 56 .

[48] Whitt-Glover MC, Goldmon MV, Gizlice Z, Heil DP, Karanja N. Learning and developing individual exercise skills (L.A.D.I.E.S.) for a better life: A church-based physical activity intervention baseline participant characteristics. Ethnicity \& Disease. 2017; 27:257-64.

[49] Assari S, Nikahd A, Malekahmadi MR, Lankarani MM, Zamanian H. Race by gender group differences in the protective effects of socioeconomic factors against sustained health problems across five domains. J Racial and Ethn Health Disparities. 2017; 4: 884-94.

[50] Booth FW, Roberts CK, Laye MJ. Lack of exercise is a major cause of chronic diseases. Compr Physiol. 2012; 2: 1143-1211.

[51] Singh PN, Clark RW, Herring P, Sabate J, Shavlik D, Fraser GE. Obesity and life expectancy among long-lived Black adults. J Geronotol A Biol Sci Med Sci. 2014; 69: 63-72.

[52] Sebastião E, Chodzko-Zajko W, Schwingel A. The need to modify physical activity messages to better speak to older African American women: a pilot study. BMC Public Health. 2015; 15: 962.

[53] Siddiqi Z, Tiro JA, Shuval K. Understanding impediments and enablers to physical activity among African American adults: a systematic review of qualitative studies. Health Educ Res. 2011; 26: $1010-24$.

[54] Lee LL, Arthur A, Avis M. Using self-efficacy theory to develop interventions that help older people overcome psychological barriers to physical activity: a discussion paper. Int J Nurs Stud. 2008; 45: 1690-1699.

[55] Anshel MH, Smith M. The role of religious leaders in promoting healthy habits in religious institutions. J Relig Health. 2014; 53: 1046-59.

[56] James DCS, Harville C, Efunbumi O, Babazadeh I, Ali S. You have to approach us right: A qualitative framework analysis for recruiting African Americans into mHealth research. Health Educ Behav. 2017; 44: 781-90.

[57] Allen K, Morey MC. Physical Activity and Adherence. In: Bosworth H. (eds) Improving Patient Treatment Adherence. Springer, New York, NY. 2010. Pg. 9-38.

[58] Dyrstad SM, Hansen BH, Holme IM, Anderssen SA. Comparison of self-reported versus accelerometer-measured physical activity. Med Sci Sports Exerc. 2014; 46: 99-106. 